\title{
Det sublime og det skjønne som estetisk kvalitet i nyere norsk bildebokkritikk
}

http://urn.kb.se/resolve?urn=urn:nbn:se:sbi-30

Citation: Nordic Journal of ChildLit Aesthetics, Vol. 2, 2011 DOI: 10.3402/

blft.v2i0.5833

Abstract: This article analyses a specific number of picture book reviews on prize-winning Norwegian picture books from 1998-2008. The subject for the analysis is to examine what kind of aesthetic thinking that is expressed in the reviewer's judgement of the book. I found that it was possible to relate the reviews to two well established concepts in classic aesthetic theory, namely the concept of the beauty and the sublime. To illustrate this I have studied more exhaustive a smaller number of reviews on two different books.

Keywords: picturebooks, literary criticism, aesthetic theory, the beauty, the sublime

Til tross for at det i Norge siden midten av 1970-tallet har vært økt oppmerksomhet om barnelitteraturens estetiske kvaliteter, så er det først fra midten av 1990-tallet at diskusjon rundt den norske barnelitteraturkritikken for alvor er blitt satt på dagsorden. I artikkelsamlingen Det glatte lag: tanker om litteraturkritikk (1996) dreier kun Linda Hambros bidrag seg om barnelitteraturkritikk. Hambro spør om det ikke er "på tide vi gjør plass til det usynlige barnet" (Hambro 1996, 199), altså barnelitteraturkritikken. Fire år seinere spør Karin Beate Vold om vi bør "stille andre spørsmål til barnebokkritikken" (Vold 2000, 9). Vold har analysert hele 1997-årgangens barnebokkritikk og svarer at barnebokkritikken må kunne diskuteres i lys av de samme kriterier som annen litteraturkritikk. Med Årboka: litteratur for barn og unge (1998-2010) og oppstarten av nettstedet barnebokkritikk.no (2003-), får så barnebokkritikken en egen faglig arena. I tillegg til de siste tiårs insistering på at også barnelitteraturen bør og kan leses med henblikk på litteraturens estetiske kvaliteter, er det grunn til 
å tro at den økte interessen for å skrive og diskutere barnelitteraturkritikk også henger sammen med at flere forskere har barne- og ungdomslitteratur som arbeidsområde og forskningsinteresse.

Mot dette bakteppet skal jeg studere et utvalg bildebokmeldinger av bildebøker som er blitt tilkjent offentlig estetisk verdi. Og med det for øye skal jeg undersøke hvorvidt det er mulig å lese ut av denne kritikken en felles forståelse av bildebøkenes estetiske kvaliteter og om bildebøkene vurderes ut fra et begrep om estetisk kvalitet. Det primære materialet for denne artikkelen er derfor et korpus på 62 meldinger av bildebøker som i perioden 1998-2008 mottok det norske kulturdepartementets pris for beste bildebok (se oversikt til slutt $\mathrm{i}$ artikkelen). For at ikke pristildelingen skulle kunne ha påvirket kritikernes vurderinger, har jeg kun studert meldinger som er publisert før det ble kjent at bøkene ville få pris. Et mulig spørsmål, som denne artikkelen ikke svarer på, er hvorvidt bøkene ble prisbelønt på grunn av kritikernes vurderinger. Meldingene er samlet ved hjelp av Retrievers mediearkiv, klipparkivet ved Norsk barnebokinstitutt og nettstedet barnebokkritikk.no.

Jeg har ikke vært opptatt av å vurdere om kritikernes vurderinger er plausible eller holdbare. Det jeg undersøker er hoordan kritikerne beskriver kvalitet og hvordan de begrunner vurderingen av boken. Helt konkret har jeg systematisk registrert og samlet alle utsagn som eksplisitt inneholder vurderende formuleringer. Jeg har derfor utelukket forfatteropplysninger, kunnskap om tidligere bøker og den bilde- og barneboktradisjonen boken er en del av, samt kritikernes analyser og tolkninger av enkeltelementer eller boken som helhet. Jeg er selvsagt klar over at tolkning og analyse er bestanddeler ved enhver vurdering, og, som Erik Bjerck Hagen skriver i boken Litteraturkritikk: en introduksjon (2004), at "både tolkning og vurdering oppholder seg ved de samme tekstlige elementene" (Bjerck Hagen 2004, 21). Likevel mener jeg det er mulig å skille ut en type eksplisitt vurderende elementer i meldingene. Ved en sammenstilling av vurderingselementene i forhold til den enkelte bildebok, antyder denne undersøkelsen et svar på hvorvidt meldingene rommer en felles forståelse av bildebøkenes estetiske kvaliteter og om bildebøkene vurderes ut fra et begrep om estetisk kvalitet.

\section{Estetikkteoretiske overveielser}

Estetikkbegrepet har rot i det greske ordet for åndedrett og det er vanlig å vise til det greske aisthesis og betydningen "den kunnskap 
som kommer gjennom sansene" for å forklare hvordan Alexander Gottlieb Baumgarten i sitt verk Aesthetica (1750-58) kunne bestemme estetikk som vitenskapen om den sanselige erkjennelse (Baumgarten 2008, 13). Med det fullkomment estetiske mente Baumgarten det skjønne. Til diskusjonen om det estetisk hører altså diskusjonen om det skjønne. Samtidig som Baumgarten arbeidet med sitt verk, arbeidet Edmund Burke med boken A philosophical enquiry into the origin of our ideas of the sublime and beautiful (1757). I dette arbeidet er Burke opptatt av å skille mellom det skjønne og det sublime. Ifølge Burke er det sublime fundert i smerte og det skjønne i velbehag. Av disse følelsene er tanken på smerte sterkere enn tanken på velbehag fordi smerte og fare ifølge Burke sorterer under det han bestemmer som selvoppholdelsesdriften (selfpreservation) (Burke 1995, 56-66). Det skjønne og det sublime forklares som motsetninger: små dimensjoner er skjønne, mens store er sublime. Det balanserte, delikate, lyse og klare er skjønt, mens det skakende, kompakte, mørke og dystre er sublimt. Likeledes er det skjønne formfullendt og endelig, mens det sublime er formløst og uendelig.

Når jeg setter de eksplisitte vurderinger i mitt materiale sammen med ulike begreps- og kvalitetsdiskusjoner i etablert estetisk teori, mener jeg å finne at kritikernes valg av vurderende karakteristikker baserer seg på kvalitetskriterier som kan forankres enten i et begrep om 'det skjønne' eller et begrep om 'det sublime' - og da i en nokså klassisk forståelse av disse begrepene. Det vil si slik disse forklares og forstås av Burke.

For her å kunne gjøre et dypdykk i deler av materialet, har jeg avgrenset undersøkelsen til å gjelde Ingeborg Mjør, Randi Brenden, Ola By Rise og Anne Schäffers meldinger av Hans Sande og Gry Moursunds Arkimedes og brødskiva (2000) som jeg vil hevde vurderes etter kriterier for sublim kunst; og til Turid Larsen, Marianne Lystrup, Morten Haugen, Kristine Isaksen, Petra J. Helgesen og Geir Vestads meldinger av Stein Erik Lunde og Øyvind Torseters Eg kan ikkje sove no (2008) som jeg mener vurderes etter kriterier for skjønn kunst.

I tillegg til Burkes Enquiry har jeg forholdt meg til Philip Shaws The sublime (2006). Shaw tar både for seg det sublimes begrepshistorie og er opptatt av å vise at nyansene i måten begrepet brukes på fortsatt er produktive. Også Jean-François Lyotard er i essayet "Det sublime og avantgarden" (1988) opptatt av at Burkes forståelse av det sublime er fruktbar for forståelsen av moderne kunst. Siden undersøkelsen av de ulike meldingene har empirisk karakter, vil jeg først sammenlikne og kommentere meldingene av henholdsvis Arkimedes og brødskiva og Eg kan ikkje sove no. Slik synliggjør jeg 
både hva jeg fester meg ved i de ulike meldingene, hva som står fram som kritikernes vurdering, og hvordan disse vurderingene blir begrunnet med beskrivelser av både detaljer og mer overordnete trekk ved bildeboken. Først når materialet er presentert skal jeg sette kritikernes vurderinger i sammenheng med Burkes undersøkelse av begrepet om det sublime og det skjønne for å vurdere hvorvidt der er en sammenheng mellom deres vurderinger og Burkes undersøkelse.

\section{Rar, stygg, grotesk}

Det er påfallende felles for alle meldingene av Arkimedes og brødskiva at de vier mer plass til Moursunds illustrasjoner enn til Sandes tekst. Indirekte kommer likevel vurderinger av teksten til uttrykk i vurderingene av forholdet mellom tekst og illustrasjoner. Blant annet skriver Mjør at "[t]ekst og bilde kler kvarandre godt i denne artige og sprelske bildeboka" (Mjør 2000) og By Rise hevder at ser man godt på både ord og bilde "blir dette heilskap og spenst" (By Rise 2000). Også Schäffer mener "[t]ekst og bilde henger fint sammen" (Schäffer 2000). Det er også først og fremst illustrasjonene som legges til grunn for de mer helhetlige vurderingene av boken som utradisjonell. Flere meldere understreker sammenhengen mellom hovedpersonen Eurekas uredde undersøkelse av etablerte naturlover med Moursunds eksperimenterende forhold til bildekunstens lover for framstilling av perspektiv og rom. Denne sammenhengen fungerer også som begrunnelser for hvorfor resultatet av samarbeidet mellom forfatter og illustratør ikke akkurat er "poetisk og melankolsk" (Mjør 2000), men i stedet "humoristisk, originalt - og litt vilt" (ibid.). At boken er original er en karakteristikk som går igjen i vurderingen av både tekst og illustrasjoner. Fortellingen blir av kritikerne beskrevet både som "fantasifull" (Brenden 2000), "original og litt pussig" (Mjør 2000). Kanskje kan By Rises vurdering av teksten som "ein tekst med mykje undring og galskap" (By Rise 2000) leses som synonymt med at den er original. Kritikerne synes enige $i$ at teksten på et vis er humoristisk og bruker ord som burlesk og karikatur for å beskrive humoren. Sammen med ord som grotesk og anarkistisk er dette beskrivelser som også brukes i forbindelse med illustrasjonene. Det er altså en sammenheng mellom de litt grove karakteristikkene av teksten og forholdet mellom tekst og illustrasjoner og de atskillig mer detaljerte og nyanserte beskrivelsene og vurderingene av illustrasjonene. Det synes som kritikerne mener at det er illustrasjonene som tar ut eller får fram tekstens potensial, og at uten illustrasjonene, ville ikke boken blitt vurdert som like estetisk vellykket. 
Gitt at det er Moursunds illustrasjoner som virkelig gjør denne boken verdt kulturdepartementets pris, kan det kanskje synes underlig at den overordnete vurderingen av Moursunds illustrasjoner er at de er stygge, et ord som går igjen i flere av meldingene. Vi kan kanskje si at kritikerne oppvurderer det stygge i sine vurderinger, og det som skaper det stygge, ifølge kritikerne, er det utradisjonelle og anarkistiske, det karikerte, det rare, det burleske og det groteske. At illustrasjonene er rare, ser ut til å ha med at "[t]radisjonelle reglar for perspektiv og rom er sette til sides" og at "proporsjonar og dimensjonar gjer Moursund nett som ho vil med" (Mjør 2000). Det er kanskje Moursunds brudd eller utprøving av "reglane for visuell kommunikasjon" (ibid.) som får Mjør til å kalle bildene, og By Rise til å kalle illustratøren for anarkistisk. Men det rare, utradisjonelle og anarkistiske henger også sammen med karakteristikken 'karikatur'. Brenden skriver at "[i]llustrasjonane kan gjerne kallast 'stygge'. Som karikaturar flest er heller ikkje desse glatte og pene" (Brenden 2000). Mer konkret forklares illustrasjonenes karikaturpreg med illustratørens bruk av sterke farger (Mjør 2000), "flater og små detaljar" (Brenden 2000), "dristige farger [...] utsnitt og perspektiv [...] rare kroppar [og] underlege merke på badebuksene" (By Rise 2000). Også Schäffer trekker fram liknende trekk ved illustrasjonene. Hun beskriver boken på følgende måte: "Store bilder, gouacher, rare utsnitt og perspektiv [...] Barnslig strek, røff, uten å være naivistisk" (Schäffer 2001).

Få kritikere vurderer boken i forhold til potensielle lesere, men Brenden skriver at illustrasjonene av og til "avdramatiserer [...] ein tekst som kan bli vel spennande for eit lite barn - og stundom understrekar dei det skumle og farlege" (Brenden 2000). Kanskje er det også bokens effekt på leseren By Rise har i tankene når han skriver om illustrasjonene at de er" $[\mathrm{g}]$ rotesk mange stader, men ikkje skremmande" (By Rise 2000).

\section{Kritikken, Burke og det sublime}

Siden det sublime første gang, for nesten tusen år siden, ble drøftet i Pseudo-Longinos' Om det sublime (Longinos 1968), har det vært gjenstand for kun små betydningsendringer og forklares stadig som det som er kraftfullt og stort, det som griper, rykker og skaker. Den opprinnelige betydningen av begrepet sublimis finner vi i sammenstillingen av sub som betyr oppå, på toppen av og limen som betyr en dørs øverste kant eller flate. Sublimis betyr altså helt opp til toppen av døren, altså mot en grense for hva som kan nås, en kant der noe 
kan bikke over. Dette aspektet ved begrepets betydningshistorie synes også som det absolutt mest grunnleggende ved begrepets ulike bruks- og forståelsessammenhenger. Shaw skriver at:

[...] whenever experience slips out of conventional understanding, whenever the power of an object or event is such that words fail and points of comparison disappear, then we resort to the feeling of the sublime. As such, the sublime marks the limits of reason and expression together with the transcendent [...] (Shaw 2006, 2).

Burke beskriver den sublime følelsen som en kroppslig erfaring knyttet til den lettelse (delight) som følger av bortfall av smerte og forbløffelse (astonishment). Dette er kanskje det vi i hverdagsspråket kaller skrekkblandet fryd. Når vi skremmes i eller av kunsten, vil vi kjenne lettelse over å oppdage at kunsten er etterlikning, at det vi erfarer i kunsten ikke møter oss i det virkelige liv. Kan kritikernes vurderingerav Arkimedesog brødskiva som bådestygg, grotesk, burlesk og humoristisk, ses i lys av dette? Er det humoren som gjør møtet med galskapen, det skremmende og det rare utholdbar og som igjen bevirker at leseren (barnet) ikke går til grunne i bildeboken, men får sin selvoppholdelsesdrift styrket? Gjør humoren det groteske mindre skremmende, og er den årsaken til leserens opplevelse av lettelse eller delight.

Skrekkfølelsen er det, som ifølge Burke, virkelig, direkte eller indirekte, styrer det sublime:

Allt som på något vis är lämpat att väcka tankar på smärta och fara, det vill säga allt som är på något sätt skräckinjagande, eller som berör skräckinjagande föremål, eller som verkar på samma vis som skräcken är en källa till det sublima (Burke 1995, 67).

Burkes refleksjon over det sublime er altså en refleksjon over hva, ved kunsten, som skaper denne skrekkfølelsen. Det er ikke umiddelbart enkelt å finne et system eller en indre sammenheng i Burkes gjennomgang av det han kaller kildene til det sublime. Momentene presenteres tilsynelatende usortert, på ulike nivåer. Etter en nærmere gjennomgang synes likevel noen momenter mer overordnete enn andre. I mine øyne er alt det som har med det grenseløse, ikkekontrollerte og utemmete overordnete momenter. De øvrige momentene blir etter min mening mer spesifikke kilder som understøtter hovedmomentet. Når Burke forklarer hvorfor store 
størrelser og vidstrakte flater er kilder til det sublime, forbinder han det med følelsen av noe grenseløst eller uendelig. Det samme gjelder for beskrivelsen av det storslagne som kilde til det sublime. Også det storslagne mangler mål og orden, en mangel som bevirker kaos, altså ikke-kontroll.

Ser vi tilbake på hva kritikerne skrev om illustrasjonene spesielt, finner vi at de nettopp la vekt på hvordan disse var store, eller utformet på store flater, hvordan de eksperimenterte med rare utsnitt og regler for framstilling av perspektiv og rom, og at denne eksperimenteringen også kunne legges til grunn for å kalle bildene for anarkistiske, og Sande og Moursund for frimodige, opprørske anarkister. Lyotard hevder det er en sammenheng mellom Burkes refleksjon over det sublime og avantgardens kunstneriske eksperimentering (Lyotard 2008, 482). Denne sammenhengen gir rom for å forstå det sublime som en type kunstnerisk eksperiment med konvensjoner og at dette eksperimentet i seg selv er en kilde til skrekk eller sjokk.

Andre momenter eller detaljer som kan være kilde til det sublime, og som, slik jeg ser det, understøtter inntrykket av det ikke-kontrollerte, er bruken av sterke farger, av vekslinger mellom lys og mørke, og bruken av lyd. Kritikerne beskriver illustrasjonene som fargesterke og illustratøren som dristig i fargebruken. En kritiker nevner at det i Arkimedes og brødskiva er brukt typografiske virkemiddel: "inne i boka leikar teksten seg rundt på sidene, med orda i ulike storleik (sic.)" (By Rise 2000). Kanskje kan slike virkemiddel uttrykke både lydstyrke og bevegelse.

Felles for de nevnte kildene til det sublime er at de er sterkest når de opptrer plutselig, når de tar del i brå, raske overganger og vekslinger. Om illustrasjonene i Arkimedes og brødskiva skriver Brenden at "[s]om karikaturar flest er heller ikkje desse glatte og pene" (Brenden 2000). Kanskje kan kritikernes beskrivelse av Arkimedes og brødskiva som karikatur ses i sammenheng med dette: Å karikere er å fordreie og forvrenge ved overdreven, overlesset eller forstørret framstilling av den eller det som er emne for karikaturen. Effekten av en karikatur er som regel ment å være komisk eller satirisk. Når noe forvrenges, framstilles det skeivt, som vridd ut av naturlig stilling. Resultatet av å forvrenge og å fordreie, blir altså rart, utradisjonelt, ikke-kontrollert. Vri og forvrenge er en type handling som forbindes med makt, voldsomhet, hardhet og bråhet. Når kritikerne beskriver hele boken, eller elementer ved boken som karikatur, kan det støtte en lesning av meldingene som svarende til Burkes oppfatning om at en kilde til det sublime i kunsten har med hurtige vekslinger og plutselighet å gjøre. 
Kritikerne forholder seg til mange av Burkes bestemmelser av det sublime. Vurderingene av bokens effekt på leserne svarer også godt til Burkes begrep om delight (lettelse). I omtalene av Arkimedes og brødskiva legges det vekt på den frisettende humoren i boken, at den er "burlesk" (Brenden 2000) og "original eller litt pussig" (Mjør 2000). Jeg vil hevde at det kritikerne her skriver om kan forstås som en variant av Burkes delight.

\section{Vakker, poetisk, sober}

De seks meldingene av Eg kan ikkje sove no er svært samstemte i sin vurdering av boken som helhet. "[E]i vakker bok" (Helgesen 2009) skriver Helgesen, og samspillet mellom tekst og illustrasjoner beskrives av Larsen som "nydelig" og "vellykket" (Larsen 2008). Det helhetlige uttrykket beskrives også som "enkel og sober" (ibid.) og ifølge Lystrup har "boka [...] ei poetisk kraft i både bilete og tekst" (Lystrup 2008).

Et generelt trekk ved meldingene i korpuset er at det blir viet mer plass til omtale og vurdering av illustrasjonene enn det det ofte er blitt hevdet at kjennetegner bildebokkritikken. Ikke bare påpekes det hvor sterkt illustrasjonene bidrar til å understreke, kle og støtte teksten eller historien, kritikerne legger også fram for leseren tolkninger og vurderinger av illustrasjonene alene. Om Torseters papirklippkollasjer heter det at de "bidrar sterkt til å understreke historiens såre stemning av ensomhet og alvor, med en klar stripe av lys" (Haugen 2008), men også at Torseter støtter opp om tekstens realisme "samstundes som han gir dei enkle orda utvida meining" (Helgesen 2009).

Foruten de mer detaljerte beskrivelsene og vurderingene av Torseters illustrasjoner, er de fleste kritikerne opptatt av å synliggjøre at de har kunnskap om Torseters teknikk. Kan hende er det like mye håndverket som kollasjenes estetiske kvaliteter som begeistrer den kritikeren som hevder at "Torseteres tredimensjonale papirklippcollager er i mesterklasse" (Haugen 2008). Med unntak av Isaksen, er det få kritikere som våger seg på en detaljert tolkning av ett eller flere oppslag i boken. De fleste formulerer seg mer generelt om hvordan illustrasjonene "er med på å skape den såre og triste stemninga i boka" (Isaksen 2008) eller er "ekspanderande [og] gir eit symbolsk lag til ein konkret tekst, og dei opnar for fleire tydingar" (Helgesen 2009).

De mer nyanserte beskrivelsen og vurderingene av Torseteres illustrasjoner legger vekt på at strekene er "florlette" (Larsen 2008), fargevalget "nøysomt" (ibid.), helheten er "gjennomført" (Lystrup 
2008), uttrykket "lyrisk" (Vestad 2009), eller at det "må være noe av det vakreste Torseter har skapt" (ibid.).

Mens teksten sies å ha "mørke undertoner" (Larsen 2008) og historien forklares som dreining "om sorgens rastløse uro og melankoli" (Haugen 2008), er det kun få kritikere som knytter denne typen karakteristikker til illustrasjonene. Et unntak finner vi likevel i Lystrups "dei mollstemte bileta " (Lystrup 2008). Kritikerne legger også særlig vekt på at teksten er "enkel og antydende" (Larsen 2008) og at den "er skoren ned til eit minimum" (Lystrup 2008) og "prega av korte setningar og knappe dialoger" (Isaksen 2008). Helgesen hevder at "Lunde skriv nedtona og konkret i eit realistisk barneperspektiv" (Helgesen 2009) og en annen kritiker hevder at" [s] pråket og stemmen i historien er presis, gjennomarbeidet og helt ut dekkende" (Haugen 2008).

Kritikerne samler seg om beslektede adjektiv som nøktern, minimal, sober, enkel og nedtont. Flere finner en sammenheng mellom disse beskrivelsene og de mer generelle vurderingene av boken som nydelig, vakker og poetisk. Når det gjelder forholdet mellom tekst og illustrasjoner, legges det vekt på at det er balanse mellom de ulike kunstnernes uttrykksformer. I meldingene finner vi kun få spor av bildebokens virkning på leseren, men Isaksen skriver at boken "treff kjensleregisteret til leseren" (Isaksen 2008) og Helgesen mener det er "ei trygg og god bok" (Helgesen 2009) og at kombinasjonen av tekstens fokus på forholdet mellom gutten og faren og illustrasjonenes fokus på vinterskogen utendørs "skaper ein nydeleg balanse mellom varme og sårheit" (ibid.).

\section{Kritikken, Burke og det skjønne}

Baumgarten forstod det skjønne som både knyttet til objektet og til blikket som ser. Når Kjersti Bale i boken Estetikk: en innføring (2009) diskuterer innholdsendringene i begrepet skjønnhet, har hun fokus på objektet. Skjønnhet forstått i forhold til det vurderende subjekt legger hun til diskusjonen av begrepet smak. Selv om estetisk teori fra 1700-tallet av har "vist at en gjennomtenkning av begrepet skjønnhet må ta utgangspunkt i det betraktende subjektet" (Bale 2009, 49), så finnes det både

i kunsten og i dagligtalen [...] lagret mer og mindre glemte, men ikke desto mindre virksomme forestillinger om at skjønnhet har med egenskaper ved objektet å gjøre, og at disse egenskapene har en naturlig sammenheng med hva vårt blikk oppfatter som attraktivt (ibid.). 
I de undersøkte bildebokmeldingenes vurdering av bildeboken som skjønn, forankres skjønnheten i det estetiske objektet. Bildebokkritikerne artikulerer det skjønne gjennom begreper som harmoni og balanse i forhold til bildenes formspråk og fargebruk og språkets poetiske kvaliteter.

Før Burke gir seg i kast med skjønnhetens sanne årsaker, ser han seg nødt til å gjøre det klart hva som ikke er årsak eller kilde til det skjønne. Med eksempler både fra plante- og dyreriket argumenterer han grundig for at bestemte proporsjoner eller faste mål og størrelser ikke er årsak eller kilde til det skjønne. Burke hevder også at begrepene formålstjenelig (fitness) og fullendelse (perfection) er knyttet til det han kaller proporsjonsdoktrinen og at heller ikke disse kan brukes til å forklare det skjønne.

Selv om det vi forstår som skjønt ifølge Burke ikke er et resultat av vår fornuft og ikke er forbundet med praktisk nytte, kan skjønnhet være en egenskap ved tingene som påvirker oss. Det skjønne er det som framkaller kjærlighet; og skjønnhet i nød er den mest tiltrekkende. Også det svake og sårbare vekker kjærlighet. Med utgangspunkt i dette legger Burke nærmest fram en katalog over det han kaller skjønnhetens sanne årsaker. Han argumenterer for at det som er skjønt er lite eller smått. Blant annet viser han til at "älskade föremål i de flesta språk omtalas med diminutiver" (Burke 1995, 165) som det engelske 'darling' som betyr 'den lille kjære'. At noe er lite og sårbart gjør det gjerne også skjørt, og det Burke kaller delicacy er en kilde til skjønnhet (op.cit., 169). Den kanskje viktigste kvaliteten ved det skjønne er, ifølge Bruke, det skjønnes glatthet (smoothness) (op.cit., 166). Det som er skjønt er ikke karakterisert ved ujevnheter, skarpe kanter eller brå vridninger. Alt er balansert og endringer skjer gradvis. Det skjønne har kurver hvis begynnelse og slutt er vanskelige å peke på (op.cit., 167). Til dette hører også Burkes vurderinger av det skjønne i lyd og det skjønne i forhold til det taktilt følbare som myk eller mykt, også beskrevet som en buktende overflate, ubrutt og rolig vekslende (op.cit., 177-78). Slik Burke vurderte sammenhengen mellom fargevalg og det sublime, finner han også at det skjønne kan uttrykkes i fargebruken. Det som er skjønt har klare, rene og ikke for sterke farger. Én farge må ikke dominere.

Det skjønne knyttes hos Burke altså til velbehag, kjærlighet og sårbarhet, men Burke ser også en sammenheng mellom det skjønne og melankolien. Han skriver at "[d]en passion som det sköna ger upphov till ligger faktiskt närmare ett slags melankoli än det lustiga och glada" (op.cit., 179). Ikke minst denne sammenhengen gjør det 
interessant å se nærmere på forholdet mellom Burkes begrep om det skjønne og kritikernes vurderinger av Eg kan ikkje sove no.

Kritikerne har vurdert bildeboken Eg kan ikkje sove no som vakker, vellykket og nydelig. At den er vakker begrunnes med beskrivelser som enkel, sober, nedtont og minimal. Dette er beskrivelser som finner gjenklang i det Burke skriver om det skjønne som lite, glatt, balansert og mykt. At noe er sobert vil si at det er måteholdent, nøkternt, ikke voldsomt eller kraftfullt. Men også at noe er dempet eller nedtont. Det som er dempet og nedtont har nettopp dette gradvise, ikke brå eller voldsomme, ved seg. Det som er dempet og nedtont er noe som blir mindre, noe som blir svakere, og derfor kanskje også

mer sårbart. Mens det sublime kunne kobles mot lettelse eller fryd, kan det skjønne ses i sammenheng med det mollstemte og det melankolske. Flere av kritikeren påpeker også denne sammenhengen og at illustrasjonene "er med på å skape den såre og triste stemninga i boka" (Isaksen 2008). Kritikernes mer spesifikke beskrivelser av Torseters strek som florlett og fargevalget som nøysomt føyer seg også inn under Burkes begrep om det skjønne. Vi ser altså at det i disse bildebokmeldingene er innskrevet en oppfatning av 'det skjønne' som en estetisk kvalitet.

\section{Konklusjon}

Gjennomgangen av de ulike bildebokmeldingene har vist at kritikerne ikke vurderer etter én artikulert standard for estetisk kvalitet eller én eksplisitt kunstfaglig eller estetisk teoretisk tenkning. Det er likevel grunnlag for å hevde at det ikke dreier seg om subjektive eller private vurderinger, men at kritikerne vurderer bildebøkene ut fra et uutalt eller et ubevisst forhold til den estetiske teoris skjelnen mellom det skjønne og det sublime og til estetikk som sanselig erfaring og erkjennelse. Denne stumheten når det gjelder bildebokkritikkens estetiske forutsetninger reiser et spørsmål om kritikken kanskje kunne vært tjent med en mer estetikkteoretisk gjennomtenkning av objektet for kritikerens vurdering.

Biografisk information: Nina Goga, f. 1969, førsteamanuensis Høgskolen $i$ Bergen. Ph.D. fra Universitetet $i$ Bergen med avhandlingen Kunnskap og kuriosa: merkverdige lesninger av tre norske tekstmontasjer for barn og unge. Medredaktør i boken Møte mellom ord og bilde: ein antologi om bildebøker (2001). Redaktør av Norsklæreren 2002-2005. Medforfatter av Alfabeta leseboka (2006). Har publisert en rekke artikler om nyere norsk barnelitteratur, sakprosa og litteraturteori $i$ antologier og tidsskrift. Kritiker på barnebokkritikk.no. Kontakt:nina.goga@hib.no 


\section{Oversikt over de prisbelønte bildebøkene (antall meldinger av hver bok i parentes):}

1998: $\quad$ Svein Nyhus for Pappa! (4)

1999: Arne Ruset (tekst) og Anne Kristin Hagesæther (ill.) for Over fjell, over hav (2)

2000: Hans Sande (tekst) og Gry Moursund (ill.) for Arkimedes og brødskiva (4)

2001: Tone Lie Bøttinger (tekst) og Akin Düzakin (ill.) for Min storebror apen (4)

2002: $\quad$ Lars Fiske for Kom, så løper vi (1)

2003: Gro Dahle (tekst) og Svein Nyhus (ill.) for Sinna mann (10)

2004: Øyvind Torseter for Klikk (4)

2005: Bjørn F. Rørvik (tekst) og Per Dybvig (ill.) for bøkene Kafé Haletippen (2001) (4), Værhårene (2002) (4), Rebusløpet (2003) (2), Konglesugeren (2004) (4) og Kumatpakkene (2005) (2)

2006: Stian Hole for Garmanns sommer (9)

2007: Hans Sande (tekst) og Gry Moursund (ill.) for Slangen i graset (2)

2008: $\quad$ Stein Erik Lunde (tekst) og Øyvind Torseter (ill.) for Eg kan ikkje sove no (6)

\section{Bibliografi}

Bale, Kjersti. Estetikk: en innføring. Oslo: Pax Forlag, 2009.

Baumgarten, Alexander Gottlieb. "Fra Aesthetica (1750)". I Estetisk teori: en antologi, red. Kjersti Bale og Arnfinn Bø-Rygg. Oslo: Universitetsforlaget, 2008, 11-16.

Bjerck Hagen, Erik. Litteraturkritikk: en introduksjon. Oslo: Universitetsforlaget, 2004.

Brenden, Randi. "Når naturlovene kolliderer". Melding av Arkimedes og brødskiva av Hans Sande og Gry Moursund. Dag og Tid 16.11.2000.

Burke, Edmund. Filosofisk undersökning av ursprunget til våra begrepp om det Sublima och det Sköna. Stockholm: Brutus Östlings Bokförlag Symposion, 1995.

By Rise, Ola. "Katten opp og skiva ned". Melding av Arkimedes og brødskiva av Hans Sande og Gry Moursund. Adresseavisen 24.11.2000.

Hambro, Linda. "Det usynlige barnet - den usynlige boken: kritikken av barne- og ungdomsbøker - muligheter og utfordringer". I Det glatte lag: tanker om litteraturkritikk, red. Cecilie Lund m.fl. Oslo: Aschehoug, 1996, 181-199.

Haugen, Morten. "Kloke forfattere og unike illustratører". Melding av Eg kan ikkje sove no av Stein Erik Lunde og Øyvind Torseter. Adresseavisen 01.12.2008. 
Helgesen, Petra J. "Bildebøker om saknet etter mor". Melding av Eg kan ikkje sove no av Stein Erik Lunde og Øyvind Torseter. Barnebokkritikk.no 14.01.2009.

Isaksen, Kristine. "Tung, tung, søvn". Melding av Eg kan ikkje sove no av Stein Erik Lunde og Øyvind Torseter. Bergens Tidende 15.12.2008.

Larsen, Turid. "Sobert om sorg". Melding av Eg kan ikkje sove no av Stein Erik Lunde og Øyvind Torseter. Dagsavisen 12.11.2008.

Longinos [Pseudo-Longinos]. Om det opphøyede i litteraturen. Oslo: Johan Grundt Tanum Forlag, 1968.

Lunde, Stein Erik (tekst) og Øyvind Torseter (ill.). Eg kan ikkje sove no. Oslo: Det Norske Samlaget, 2008.

Lyotard, Jean-François. "Det sublime og avantgarden". I Estetisk teori: en antologi, red. Kjersti Bale og Arnfinn Bø-Rygg. Oslo: Universitetsforlaget, 2008, 473-486.

Lystrup, Marianne. "Varm og vakker". Melding av Eg kan ikkje sove no av Stein Erik Lunde og Øyvind Torseter. Vårt Land 26.11.2008.

Mjør, Ingeborg. "Evreka, far og naturlovene". Melding av Arkimedes og brødskiva av Hans Sande og Gry Moursund. Bergens Tidende 09.10.2000.

Sande, Hans (tekst) og Gry Moursund (ill.). Arkimedes og brødskiva. Oslo: Gyldendal Tiden, 2000.

Schäffer, Anne. "Arkimedes og brødskiva". Melding av Arkimedes og brødskiva av Hans Sande og Gry Moursund. Numer 47 (2001) 1.

Shaw. Peter. The sublime. London: Routledge, 2006.

Vestad, Geir. "Vakkert om savn". Melding av Eg kan ikkje sove no av Stein Erik Lunde og Øyvind Torseter. Hamar Arbeiderblad 11.03.2009.

Vold, Karin Beate. "Bør vi stille andre spørsmål til barnebokkritikken?: nedslag i norsk barnebokkritikk, årgang 1997". Årboka litteratur for barn og unge 2000. Oslo: Det Norske Samlaget, 2000, 9-27.

Note: This article is being published simultaneously in Barnboken - tidskrift för barnlitteraturforskning/Journal of Children's Literature Research and Nordic ChildLit Aesthetics/Barnelitterært forskningstidsskrift 